VOL. 7

APRIL, 1933

No. 10

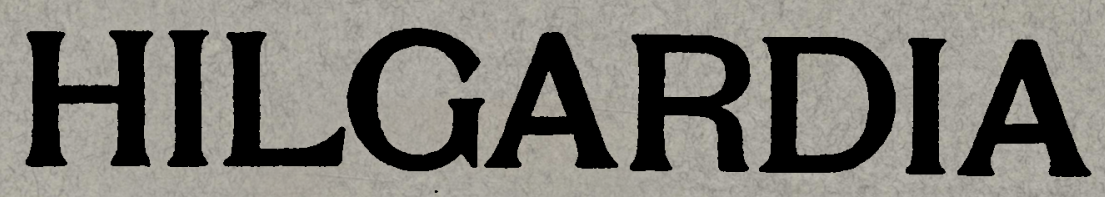

A Journal of Agricultural Science PUBLISHED BY THE

California Agricultural Experiment Station

CONTENTS

Reproduction Without Males in Aseptic Root Cultures of the Root-Knot Nematode JOCELYN TYLER

Development of the Root-Knot Nematode as Affected by Temperature

JOCELYN TYLER 
DEVELOPMENT OF THE ROOT-KNOT NEMATODE AS AFFECTED BY TEMPERATURE

JOCELYN TYLER 



\title{
DEVELOPMENT OF THE ROOT-KNOT NEMATODE AS AFFECTED BY TEMPERATURE ${ }^{1}$
}

\author{
JOCELYN TYLER2
}

\section{INTRODUCTION}

It is well known that invertebrate animals are dependent on the temperature of the environment for their vital activities. In the case of the root-knot nematode, Heterodera marioni (Cornu), this is a factor which must be considered in every phase of biological study. Since it has a direct influence on the rate of metabolism, it is obvious that it must also have an important bearing on problems to which it has not heretofore been applied, such as rate of travel through soil, rate of killing by chemicals, and rate of starvation in fallow fields, as well as on the amount of infestation and the damage done to crops, which have been investigated by Godfrey (1926) and by L. H. Jones (1932).

Temperature is not, however, the only factor influencing the rate of development of this nematode. Godfrey and Oliveira (1932) grew cowpea and pineapple plants side by side in the greenhouse. Yet under identical conditions, development to egg-laying took 35 days in pineapple and only 19 days in cowpea.

Baunacke (1922) has analyzed the effect of temperature on the sugar-beet nematode. His thesis is that the larva, which may normally survive in the soil for months without feeding, depends on a food reserve which it has stored up from the egg. When the soil is cool the larvae are fairly inactive, and the reserve will be used slowly. With higher temperatures, motion and also sense perception are accelerated, so that the larvae should be able to find host plants before the food reserves become exhausted. For the sugar-beet nematode he gives the optimum temperature as $25^{\circ} \mathrm{C}$, with a maximum activity at $28^{\circ}$. This increased activity is an escape reaction, which should in nature assist the migration of the larva to a host root or to a cooler environment. If prolonged, it causes death by exhaustion as an indirect result of the high temperature.

In the present paper, it is proposed to analyze the reactions of the root-knot nematode to temperature, as nearly as possible apart from

1 Received for publication September 26, 1932.

2 Research Assistant, Division of Entomology and Parasitology, University of California, Berkeley. 
other factors. One of the principal objects has been to determine the shortest time for development at different temperatures. The conclusions may not hold good for all hosts, as Godfrey and Oliveira (1932) have demonstrated, but the tomato plant is a very favorable host and the minimum records obtained for it are probably not far from the minimums for most other plants.

\section{METHODS OF EXPERIMENTATION}

Earliana tomato was used exclusively as the host plant. Infested roots were grown at controlled temperatures in three series of experiments, one in Pfeffer's solution and two in soil. Results were consistent throughout the three series.

The aseptic seedling cultures described in the foregoing paper (Tyler, 1933) made suitable material for temperature experiments. In order to study the behavior of individual nematodes, only one worm was used in a culture, and the time was recorded for each culture separately, starting at the first sign of gall formation, when the seedling was transplanted to a test tube containing Pfeffer's solution and placed in an incubator chamber.

In 1927, experiments were made with tomato plants growing in jars of soil, in a water bath patterned after the tanks installed at Johns Hopkins University (Livingston and Fawcett, 1920). The water was kept in continuous circulation around the jars by bubbling compressed air up from the bottom of the tank through a series of holes in a tube the length of each compartment. Battery jars were filled with infested soil from the greenhouse, subirrigated by the method of Jones and Tisdale (1921). When this soil had been brought to the desired temperature, nematode-free seedlings were transplanted into it and the records of the experiment were started. The soil temperature was guarded by an insulation of mineral wool (Jones and Tisdale, 1921). The tops of the plants were in the air of the room.

In 1931 plants were grown in the type of root cages described by Dean (1929), some in cold storage and others in an air bath heated by thermostatically controlled light bulbs, with air circulation supplied by a small electric fan. Records were started when a water suspension of active larvae was poured directly over the previously uninfested roots, where they grew along the glass at the side of the cage.

Standardized thermometers were kept in positions where they would show the actual temperatures of the roots. For soil experiments they were set into the soil at the depth of the galls. For culture-solution experiments they were placed in tubes containing tap water, two for 
each basket of culture tubes. Charts of the root temperatures were made from thermograph records checked against the thermometer readings. A fluctuation of $\pm 1^{\circ} \mathrm{C}$ was unavoidable in some of the experiments. Any wider fluctuations were only temporary. Four or five accidents occurred in the different experiments, giving a deviation of $3^{\circ}$ to $12^{\circ}$, but not reaching extreme temperatures. In most cases, the fluctuations were only a fraction of a degree beyond the limits established. The total time for both types of variation was never more than 20 per cent of the time of any of the experiments reported, and generally much less.

Moisture control was not considered necessary in the soil experiments, because this nematode thrives, especially in the gall, throughout the moisture range of good plant growth (Godfrey, 1926).

Artificial light was supplied for plants growing in soil. Some of the roots in culture solution grew as well with stem and leaves removed as did others with top parts intact.

\section{METHODS OF MEASURING DEVELOPMENT}

The stages of development from stage 3 , the free-living larva, to stage 12 , the full-grown female, are numbered in accordance with plate 1 of Bessey's paper (1911), which is reproduced in part in figure 1. After the nematode has reached stage 12 , the gelatinous oöthecal secretion is extruded from the vulva, and somewhat later small ova can be found in the oviducts. The final stage for these experiments is the extrusion of the first eggs. The metamorphosis of the male is shown in stages 13, 14 , and 15.

Each record shows the stage of development reached by one nematode in a certain number of days at a certain temperature. Since the galls were dissected for examination, only one observation could be made on each nematode, and the slower cases are open to several possible interpretations. There are individual differences in rate of development, as will be shown in connection with the rate of egg-laying. In some cases, however, development is undoubtedly arrested by unfavorable conditions, and this may have occurred some time before the examination, so that there is no way of determining when the recorded stage was reached except by comparison with other individuals at the same temperature. Allowance should also be made in soil experiments for delayed infestation. The minimum-time records are more significant because they give definite evidence of what really happened during the time of the experiment.

The time and temperature relations may be expressed in heat units. Each Centigrade degree above $10^{\circ}$, acting for one hour, is counted as 

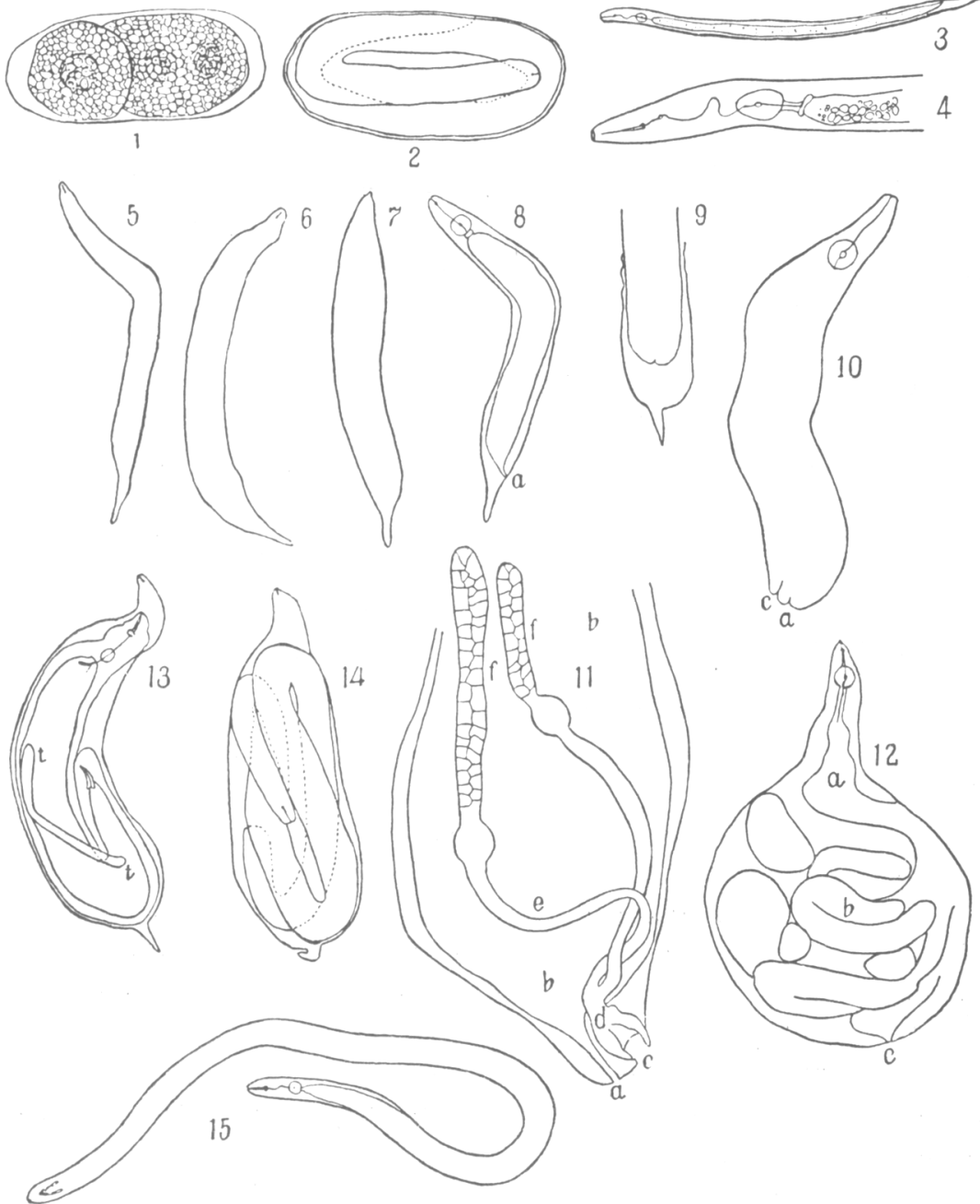

Fig. 1. Stages in the development of the root-knot nematode. [After Bessey (1911), by permission from the United States Department of Agriculture.] 1 and 2, Developing eggs. 3 and 4, Free-living larva and its anterior portion. 5 to 8, Stages in growth of larvae. 9, Posterior portion of immature female just before molting, recognized by the old larval tail which has not been stretched along with the rest of the cuticle. 10, Female after molt: $a$, anus; $c$, vulva. 11, Posterior portion of young female. 12, Full-grown female : $a$, alimentary canal; $b$, loop of oviduct; $c$, vulva. 13 and 14, Metamorphosis of male. 15, Free adult male. 
one effective unit. A temperature of $16^{\circ}$ for 24 hours is thus counted as $24 \times 6=144$ units. Summation of these units gives a measure of the heat requirements, which are approximately constant for a given stage of the life history at any medial temperature, and which increase with succeeding stages. For example, the normal range was as follows, both in soil and in culture-solution experiments : 500 heat units for gall formation by larvae ; $2,100-4,000$ for development of a nematode from the appearance of a gall to stage $9 ; 3,700-6,000$ to stage $10 ; 4,800-7,000$ to stage $12 ; 6,300-7,500$ to the formation of ova ; $6,500-8,000$ to the beginning of egg-laying; and roughly 5,000 more for the development and hatching of eggs. Shelford (1927) has pointed out several objections to the summation method. It has nevertheless a practical usefulness, and its inaccuracies are no greater than the variations shown by individual nematodes. It also emphasizes certain differences between mathematical expectations and experimental results, such as the amount of development at very low temperatures, and the different threshold relations of young and mature stages.

For any stage of development, the time and temperature records of individual nematodes at medial temperatures fall roughly into a parabolic curve (fig. 2), practically paralleling the curve of hour-Centigradedegree units. A heat-unit curve can thus be used as a working basis for predicting the time required for development at any given temperature, within the medial range, and is useful in comparing records obtained at different temperatures.

Heat units were computed empirically from $10^{\circ} \mathrm{C}$ because $11.5^{\circ}$, the " $a$ point" of the rate curve (fig. 3 ), was too high for many of the lowtemperature experiments, while $9^{\circ}$, which is close to the true threshold temperature for early development at least, is too far from this curve. The threshold of development is below the parabola and the rate curve in any case (Krogh, 1914), and parabolas calculated from $10^{\circ}$ are har-. monious with the majority of the data from experimentation.

In cultures held at $10^{\circ}$ or $12^{\circ} \mathrm{C}$ for a long period, considerable development may be shown where only a few hundred heat units are recorded. In such cases the threshold temperature is obviously below $10^{\circ}$. At these low temperatures the sum of heat units above $9^{\circ}$ is often two or three times the number computed from $10^{\circ}$, although in brief exposures at higher temperatures the difference is negligible. In such special cases, the usual computation gives a false picture of the situation, and the rate of development can be better interpreted by calculating heat units from the threshold, $9^{\circ}$. Where these are mentioned both counts are given, but unless explicitly stated heat units are computed only from $10^{\circ}$. 


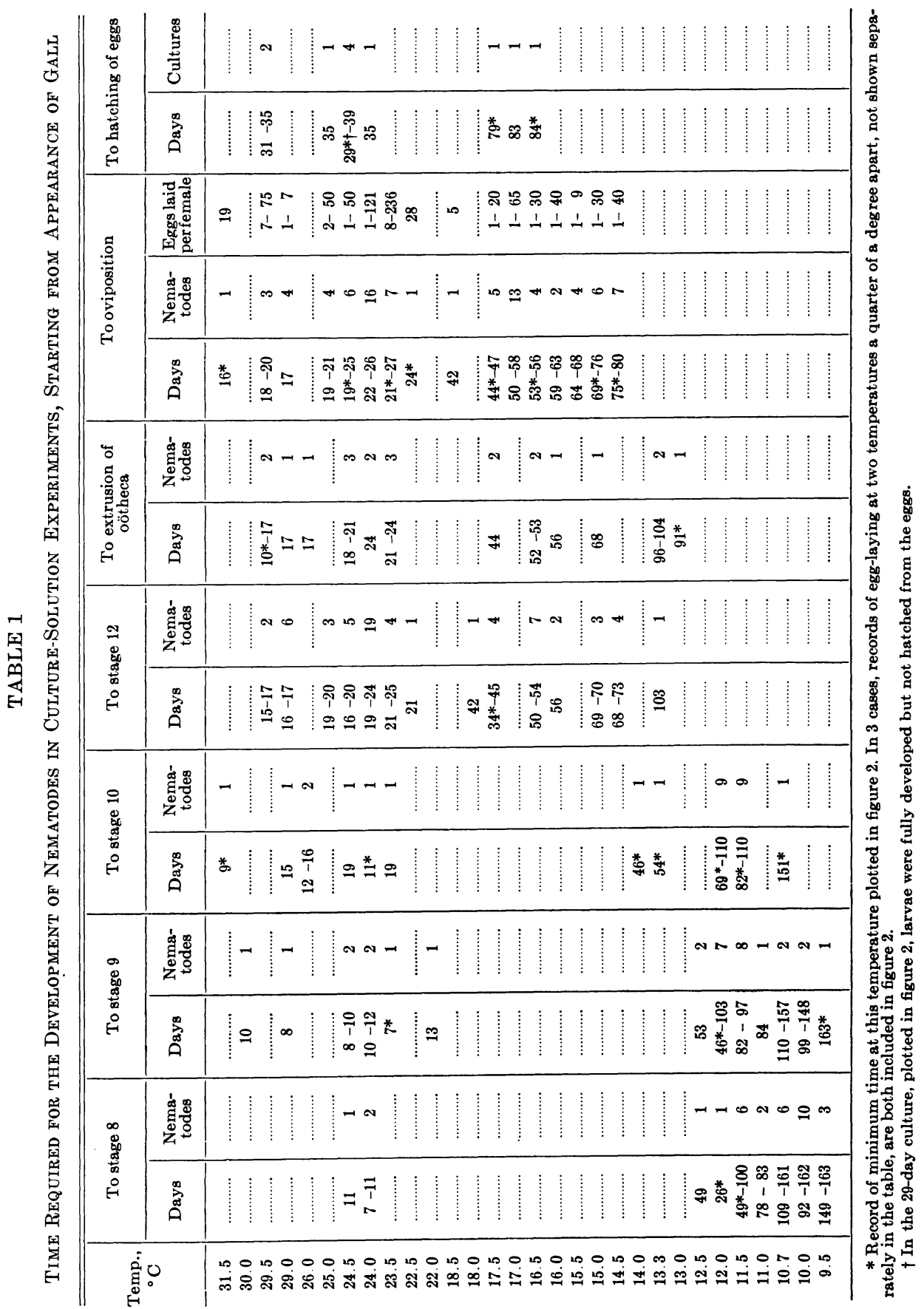




\section{RATE OF DEVELOPMENT AT DIFFERENT TEMPERATURES}

Tables 1 and 2 present the experimental data in condensed form. A wide range in rate of development is included, but the very slowest cases have been discounted and their records omitted.

From these data, examples of the most rapid rate of development for each stage have been selected for figure 2, a graph which shows the time of development at various temperatures and the relation of the different stages to the parabolas. The culture-solution experiments were started after gall formation, while the soil experiments were started with freeliving larvae. In the graph the former records have been given their proper positions in relation to the minimum time required for gall formation, represented by the parabola of 500 heat units, so that the stages of one complete life history can be pieced together from the several observations.

TABLE 2

Time of Development of Nematodes in Soll Experiments, Starting with Free-Living Larvae

\begin{tabular}{|c|c|c|c|c|c|c|c|c|c|c|c|}
\hline \multirow[b]{2}{*}{$\underset{{ }^{\circ} \mathrm{C}}{\text { Temp., }}$} & \multicolumn{2}{|c|}{ To stage 8} & \multicolumn{2}{|c|}{ To stage 9} & \multicolumn{2}{|c|}{ To stage 10} & \multicolumn{2}{|c|}{ To stage 12} & \multicolumn{3}{|c|}{ To oviposition } \\
\hline & Days & $\begin{array}{c}\text { Nema- } \\
\text { todes }\end{array}$ & Days & $\begin{array}{l}\text { Nema- } \\
\text { todes }\end{array}$ & Days & $\begin{array}{l}\text { Nema- } \\
\text { todes }\end{array}$ & Days & $\begin{array}{c}\text { Nema- } \\
\text { todes }\end{array}$ & Days & $\begin{array}{l}\text { Nema- } \\
\text { todes }\end{array}$ & $\begin{array}{l}\text { Eggs } \\
\text { laid per } \\
\text { female }\end{array}$ \\
\hline 35.5 & $7 *-8$ & 2 & 10 & 1 & & & & & & & \\
\hline 34.0 & 10 & 1 & 12 & 1 & $12^{*}$ & 1 & & & & & \\
\hline 33.5 & & & $8^{*}$ & 3 & 14 & 3 & & & & & \\
\hline 31.5 & 10 & 1 & $7^{*-13}$ & 3 & 13 & 2 & $14 *-17$ & 6 & $17 *-22$ & 5 & $1-25$ \\
\hline 30.0 & 7 & 1 & 10 & 1 & 13 & 3 & $13-16$ & 7 & $17-18$ & 2 & $17-28$ \\
\hline 28.5 & $7-10$ & 11 & $7 *-10$ & 13 & $12-14$ & 34 & $13-18$ & 53 & 17 & 7 & $1-50$ \\
\hline 28.0 & & & 10 & 1 & $10^{*}$ & 1 & $13 *-17$ & 64 & 17 & 3 & 1 \\
\hline 27.5 & $7-10$ & 21 & $7-10$ & 10 & 15 & 3 & 17 & 44 & 17 & 4 & $1-5$ \\
\hline 27.0 & $7-10$ & 9 & $7-10$ & 5 & $12-15$ & 6 & $15-17$ & 59 & $16 *-19$ & 5 & $1-15$ \\
\hline 26.5 & 8 & 4 & $10-12$ & 2 & 14 & 3 & $17-19$ & 11 & $20-21$ & 38 & $1-150$ \\
\hline 26.0 & $6-10$ & 3 & $7^{*-12}$ & 4 & $13-17$ & 6 & 19 & 1 & 21 & 75 & $2-150$ \\
\hline 25.5 & 11 & 1 & 11 & 1 & $14-16$ & 9 & $16-20$ & 37 & $20^{*}-22$ & 26 & $1-50$ \\
\hline 25.0 & $6-10$ & 13 & $8-13$ & 4 & $13-16$ & 4 & $16 *-20$ & 4 & & & \\
\hline 24.5 & 7 & 1 & 14 & 1 & $17-21$ & 9 & $20-22$ & 58 & $21-30$ & 10 & 3- 80 \\
\hline 24.0 & $6^{*}-12$ & 57 & $9-15$ & 14 & $14-20$ & 34 & $18-20$ & 3 & $\begin{array}{lll}25 & -27\end{array}$ & 25 & $15-150$ \\
\hline 23.5 & 9 & 8 & & & $19-21$ & 9 & $19 *-24$ & 24 & $\begin{array}{ll}28 & -29\end{array}$ & 9 & 25-100 \\
\hline 23.0 & $9-13$ & 14 & $13-16$ & 4 & & & & & & & \\
\hline 22.5 & $11-12$ & 4 & $11-16$ & 43 & $17-18$ & 14 & $25-26$ & 35 & 26 & 5 & $1-20$ \\
\hline 20.0 & 11 & 1 & $14^{*}$ & 1 & 25 & 1 & $26^{*}-31$ & 2 & $31^{*}$ & 1 & 15 \\
\hline 19.0 & $17-20$ & 18 & $17 *-20$ & 13 & $\begin{array}{ll}26 & -29\end{array}$ & 5 . & 38 & 4 & & & \\
\hline 15.5 & & & & & & & & & 67 & 2 & $5-35$ \\
\hline 14.0 & 44 & 1 & & & & & & & & & \\
\hline 13.5 & & & & & $56^{*}$ & 4 & 73* & 2 & & & \\
\hline 12.8 & 41 & 1 & & & & & & & & & \\
\hline 12.2 & 50 & 2 & & & & & & & & & \\
\hline
\end{tabular}

* Record of minimum time at this temperature plotted in figure 2. 


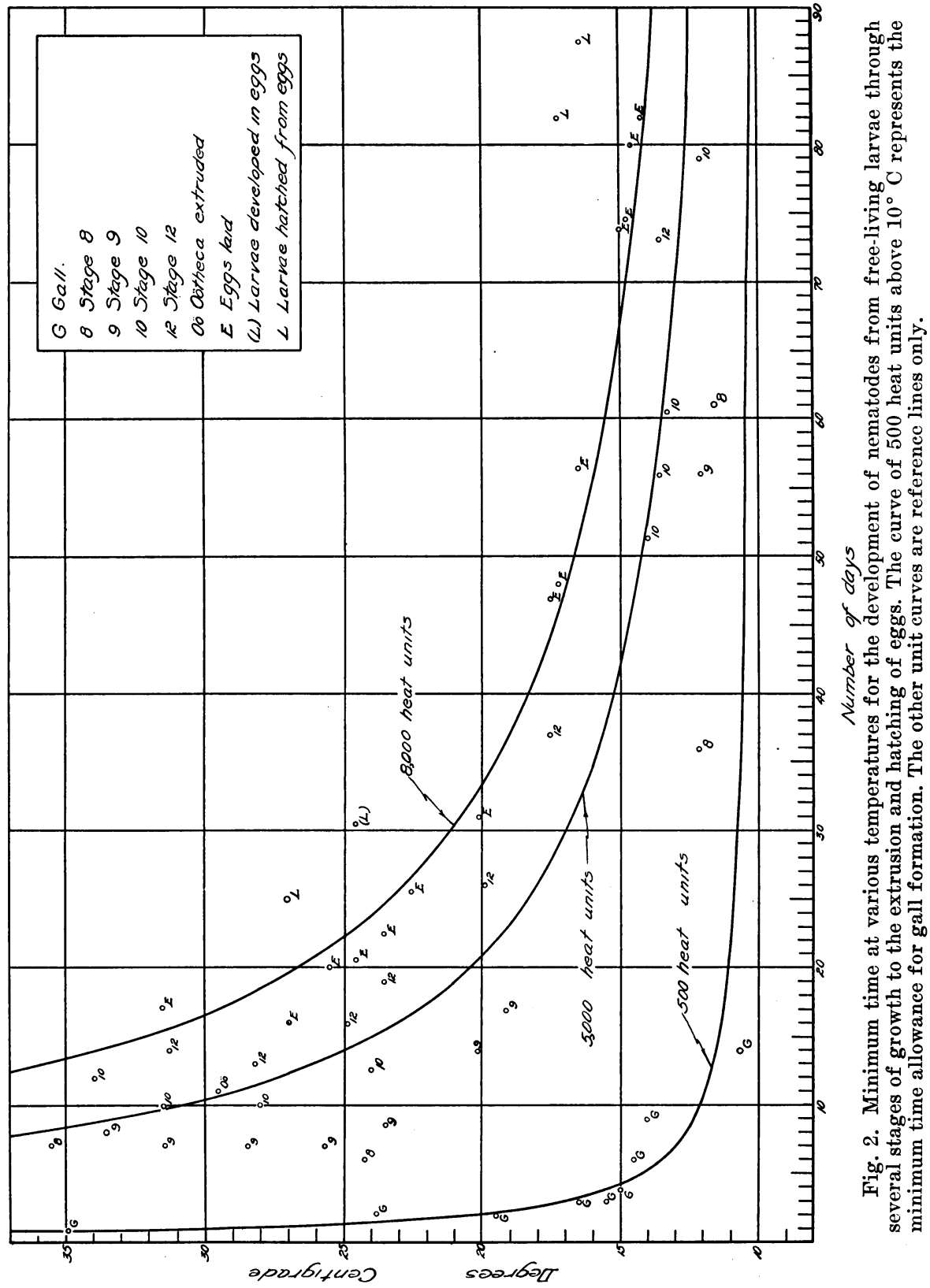


This graph (fig. 2) shows that the minimum time required for the life cycle in tomato roots from free larva to free larva was 25 days at $27.0^{\circ} \mathrm{C}$, increasing to 87 days at $16.5^{\circ}$. The minimum time from the appearance of a gall to the beginning of egg-laying was 15 days at $27.0^{\circ}$ and nearly 79 days at $14.3^{\circ}$. In the medial range the rate of increase of time with decreasing temperatures was fairly steady and regular.

TABLE 3

Variation in Amount of Development of Nematodes Under Like Conditions

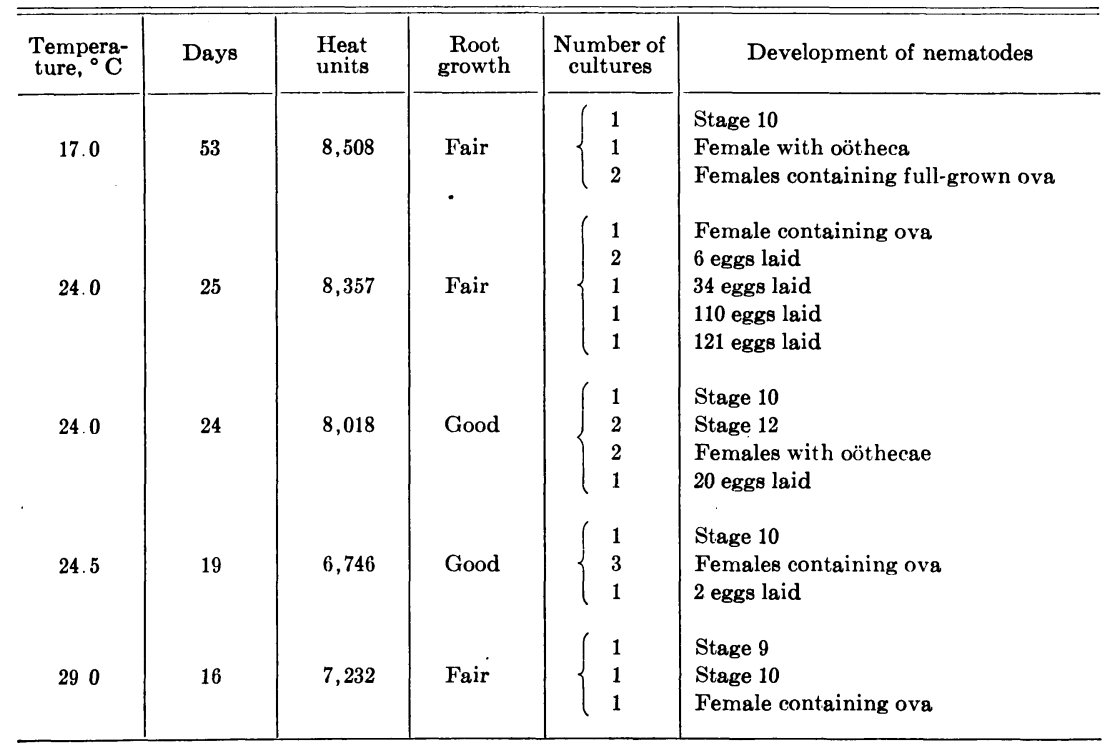

The rate of development is dependent to an appreciable extent on the factor of nutrition, which cannot be controlled without a method of completely artificial cultivation. Even at moderate temperatures there was considerable variation in rate or in amount of development in Pfeffer's solution cultures that were identical in all external conditions, including a similar amount of root growth. The data for several groups of cultures compared in this way are shown in table 3 . For each group, the galls were formed on the same day by offspring of one unmated female, and were incubated side by side. The records for $24.5^{\circ} \mathrm{C}$ show that it was possible under the conditions of that experiment for one female to lay 2 eggs and for three others to contain partly developed ova, while a fourth individual had reached only stage 10 . The slower individuals must also be considered, of course, and the average rate of development will be presented later, in connection with figure 3 . However, the minimum period of development, as shown in figure 2 by the more advanced 
individuals at the various temperatures, is of the greatest practical significance because it is experimentally the most accurate, and because of its application in control operations by the fallow-field and trap-crop methods. The differences in rate of development among cultures in the same host species and the differences found by Godfrey and Oliveira (1932) in different hosts may perhaps be interpreted as different manifestations of the fundamental relation between nutrition and rate of development.

\section{STATISTICAL PRESENTATION OF RATE OF DEVELOPMENT}

Figure 3 is a mean-velocity curve based on the data for egg-laying presented in tables 1 and 2. Each line represents a group of records averaged by the method of least squares. Temperature and rate, the reciprocal of the time of development, are the variable factors compared.

Before they were averaged, the figures were corrected in such a way that all records should cover only the time from the appearance of a gall to the first extrusion of eggs. The minimum time required for gall formation (as shown in figure 2 by the curve of 500 heat units) was therefore subtracted from the recorded time of the soil experiments; and where a female with an egg mass was found in any experiment, the recorded time of her life history was corrected by the allowance of 12 units for each egg laid, which will be explained later.

In spite of the irregularities indicated in table 3 , a correlation coefficient of 0.97 was obtained for the 279 records from $14.3^{\circ}$ to $28.0^{\circ} \mathrm{C}$. To determine the " $\alpha$ point" (Shelford, 1927), the curve for these records has been extrapolated to the temperature axis, which it cuts at $11.5^{\circ}$.

At temperatures under $16.5^{\circ} \mathrm{C}$, all the records fall below the first curve. Therefore a second curve, with an $a$ value of $10.2^{\circ}$, has been added to the graph, showing the relatively more rapid rate of development at low temperatures. Although the second curve was made from only 10 records, between $14.3^{\circ}$ and $14.8^{\circ}$, its direction is almost identical with one made from the 22 records from $14.3^{\circ}$ to $16.3^{\circ}$.

The curve for the 22 records above $28^{\circ} \mathrm{C}$, averaged separately, shows the reversal of direction which indicates that the average rate is retarded at high temperatures.

The same types of deviation from the straight line, beyond the temperature limits of normal development, have been found by other investigators (Glenn, 1922; Peairs, 1927 ; Shelford, 1927), following the observations of Krogh (1914). Shelford (1927) uses the term "medial temperatures" in referring to the temperature range within which the data from experimentation coincide with the parabola of time and temperature or with its reciprocal, the straight line of rate and temperature. 


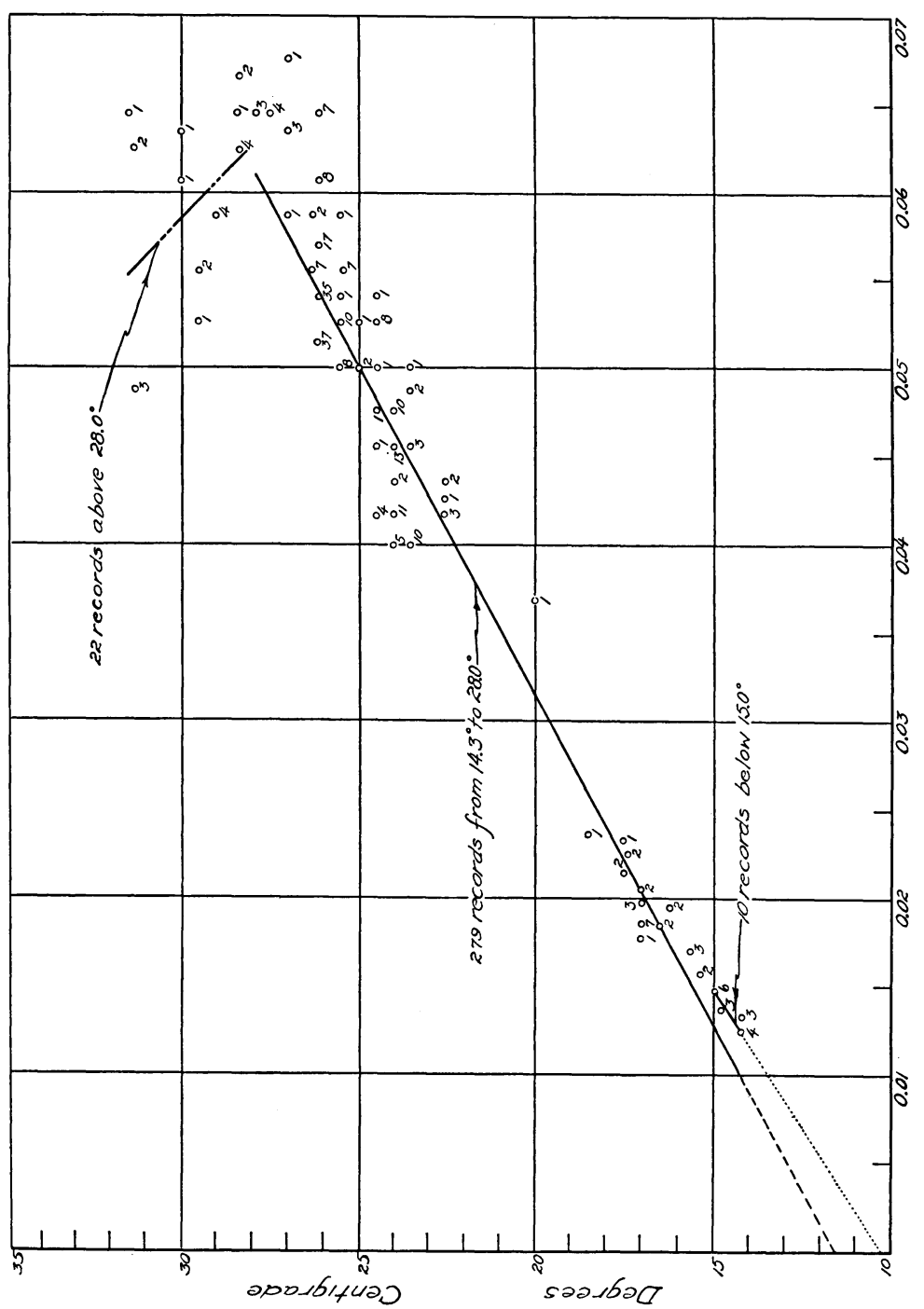

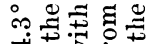

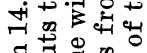

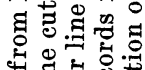

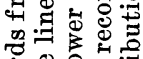

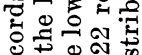
ญ承

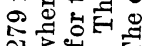
त $B$ क्ष 岁㶽驾密

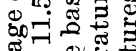

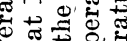
๘

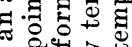
को 00 击

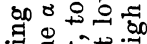

2 o $\stackrel{5}{1}$ o) के क्ष

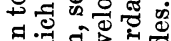

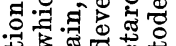
我

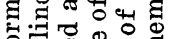
덤워 至兽

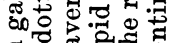
밍

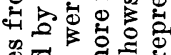
웡며유.

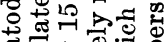

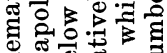

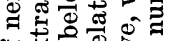
떵 勿运 빙ㅎㅇ웡 过 으월을

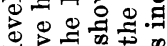
政 फुำ ำ 유

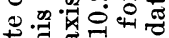

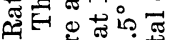

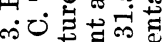

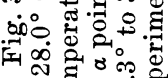

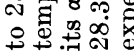




\section{THRESHOLD OF DEVELOPMENT}

An experiment was made to test the lowest temperature possible for nematode development, using newly formed galls in Pfeffer's-solution cultures. There was no development in 33 cultures kept between $7.0^{\circ}$ and $7.5^{\circ} \mathrm{C}$ for 50 to 105 days, but in similar cultures stored at this temperature for 58 to 77 days and then removed to room temperature, 5 of the 14 nematodes developed and laid viable eggs.

At $9.5^{\circ} \mathrm{C}$ there was development as far as stage 9 , so the threshold temperature must be at or below $9^{\circ}$. The roots also made some growth.

It is possible that the threshold is higher for maturity and egg formation than for the early stages of development. The velocity curve for the entire life cycle has its $a$ point at $11.5^{\circ} \mathrm{C}$ (fig. 3), and also the egg-laying records in figure 2 would be more harmonious with parabolas calculated from $11.0^{\circ}$, while stages 10 and 12 are harmonious with the parabolas represented on the graph, which were calculated from $10.0^{\circ}$. Ludwig (1928), working with the Japanese beetle, and Glenn (1922), with the codling moth, found that the egg, larva, and pupa each showed independent threshold and maximum temperatures.

\section{DEVELOPMENT AT LOW TEMPERATURES}

Eggs were laid at $14.3^{\circ} \mathrm{C}$, but the greatest development accomplished at a constant lower temperature was the extrusion of the oötheca at $13.3^{\circ}$. This occurred in 3 cultures out of the 13 which had fair root growth and sufficient time allowance. Yet at still lower temperatures, not held constant throughout the experiment, 2 females contained partly developed ova: one culture had been kept for 297 days at several steady temperatures between $7.0^{\circ}$ and $12.5^{\circ}$, with a total of 7,722 heat units abovie $10.0^{\circ}$ or 12,642 above $9.0^{\circ}$; the other had been 255 days between $7.0^{\circ}$ and $12.5^{\circ}$, plus 9 days at $14.0^{\circ}$, with 6,569 or 10,721 heat units. The failure at $13.3^{\circ}$ can probably be explained as the result of inadequate nutrition, but the possible stimulating effects of temperature changes $^{3}$ and of subthreshold temperatures (Parker, 1930) should be

3 Peairs (1927) considers that constant temperatures are unnatural, and may tend to retard development. Ludwig (1928), on the other hand, found that the Japanese beetle developed as rapidly at constant as at fluctuating temperatures, when the effects of extreme temperatures were eliminated and fluctuation took place only between the threshold and the optimum temperature. However, Cook (1927), Peairs (1927) and Parker (1930) have all found an accelerated rate of development for the insects investigated, correlated with daily fluctuations between the threshold and the optimum temperature. The nematode cultures under discussion are not exactly comparable with the experiments quoted from other authors, because the nematodes were exposed to small daily fluctuations of temperature during only a part of the period of development, and for the remaining time the temperature changes occurred at intervals of several weeks. 
borne in mind (in connection with the 2 cases where ova were formed at even lower temperatures). However, in the 10 additional cultures at irregular temperatures below $12.5^{\circ}$ which had sufficient time and root growth, only one nematode had reached even the oöthecal stage. These cases with irregular temperature records are not included in the tables or graphs, which are based exclusively on experiments at constant temperatures.

At still lower temperatures, maintained more or less constant, there were 334 cultures started at $10^{\circ}, 11^{\circ}$ and $12^{\circ} \mathrm{C}$, not all of them reported in the tables. They were examined after several months in cold storage, although their heat-unit counts were still low. Of 320 cultures with less than 4,000 heat units, 90 showed more development than would have been expected from their low unit counts, 95 showed an average rate, and 135 were either very slow or else arrested before examination. Stage 10 was reached 16 times, once with as few as 1,475 heat units above $10^{\circ}$, or 3,400 above $9^{\circ}$, the other 15 times with 2,400 to 3,600 heat units above $10^{\circ}$. The 14 cultures with longer growth time, which had accumulated from 4,000 to 5,200 units above $10^{\circ}$, showed no development beyond stage 10 .

Peairs (1927) points out that there is "an apparent loss of vitality incident to the prolonged vital period" at low temperatures. This applies both to host plant and to parasite. Nematodes probably have higher nutritional requirements for maturity and egg formation than for the early stages, while the tomato seedlings failed to continue their growth through the time required for nematode development at these low temperatures. No attempt was made to substitute some species of plant which would make a relatively better growth at low temperatures, because of the host differences found by Godfrey and Oliveira (1932), but such an experiment might give illuminating information.

TABLE 4

Gall Formation in Soll at Low Temperatures

\begin{tabular}{c|c|c|c|c|c}
\hline \multicolumn{2}{c|}{ Temperature, ${ }^{\circ} \mathrm{C}$} & \multirow{2}{*}{ Days } & $\begin{array}{c}\text { Hours } \\
\text { above 13 }\end{array}$ & \multicolumn{2}{|c}{ Nematodes } \\
\cline { 1 - 2 } Range & Average & & & Number & Development \\
\hline $9.0-12.2$ & 10.6 & $14 *$ & 0 & 1 & Stage 3 \\
$10.4-13.3$ & 12.0 & 43 & 42 & 1 & Stage 7 \\
$10.4-13.7$ & 12.2 & 56 & 171 & 2 & Stage 7 \\
$10.4-13.7$ & 12.2 & 50 & 171 & 2 & Stage 8 \\
\hline
\end{tabular}

* This record is plotted in figure 2 . 


\section{ROOT PENETRATION AT LOW TEMPERATURES}

Root penetration requires considerable activity on the part of a larva, and its occurrence at very low temperatures was not anticipated. Godfrey (1926) considered $13^{\circ} \mathrm{C}$ as the critical temperature for gall formation in roots growing in soil. A few galls found at lower temperatures in my 1927 experiments in soil are reported in table 4 . In only one case was the soil temperature below $13^{\circ}$ during the entire time of the experiment, but the others averaged around $12^{\circ}$. The first record is the only one in soil which shows the time required for gall formation, because the other experiments included a period of larval development within the roots. Experiments on gall formation in petri dishes (discussed in connection with table 10) were not made below $14^{\circ}$.

\section{DEVELOPMENT AT HIGH TEMPERATURES}

While galls were formed and development was started at temperatures as high as $35.0^{\circ} \mathrm{C}$, both in soil and in Pfeffer's-solution cultures, complete development was not obtained above $31.5^{\circ}$. In the 22 cases of egglaying between $28.3^{\circ}$ and $31.5^{\circ}$, a few individuals showed the same rate as at $27.0^{\circ}$ (fig. 3 ) ; but there was no acceleration in response to the higher temperature, and the majority showed a marked retardation.

The curve for rate of development (fig. 3) breaks sharply above $28^{\circ} \mathrm{C}$, showing that this is the optimum temperature, above which development is slower. The irregularity of distribution of the records above this temperature is an indication that the limits of normal development have been passed, although the factor of inadequate nutrition again enters at about $31^{\circ}$. Godfrey (1926) states that tomato roots show maximum gall formation at $30^{\circ}$, and that other roots vary somewhat according to the temperature of their optimum growth.

In culture-solution experiments at $36.5^{\circ} \mathrm{C}$, the roots made little or no growth and all their growing tips were killed. In 14 to 24 days, 22 nematodes made no growth at all; 12 larvae fed and started to fatten but failed to reach stage 8 ; and only 1 grew farther, a male, which died before becoming fully developed. This observation is of interest in connection with the discussion of sex ratios in the foregoing paper (Tyler, 1933 ), but it seems less significant in the temperature study.

After 9 to 16 days at $36.5^{\circ} \mathrm{C}, 7$ cultures (table 5) were given time to recover at room temperature. Although the galls were dissected with great care none of the 7 nematodes was found, and it was concluded that 


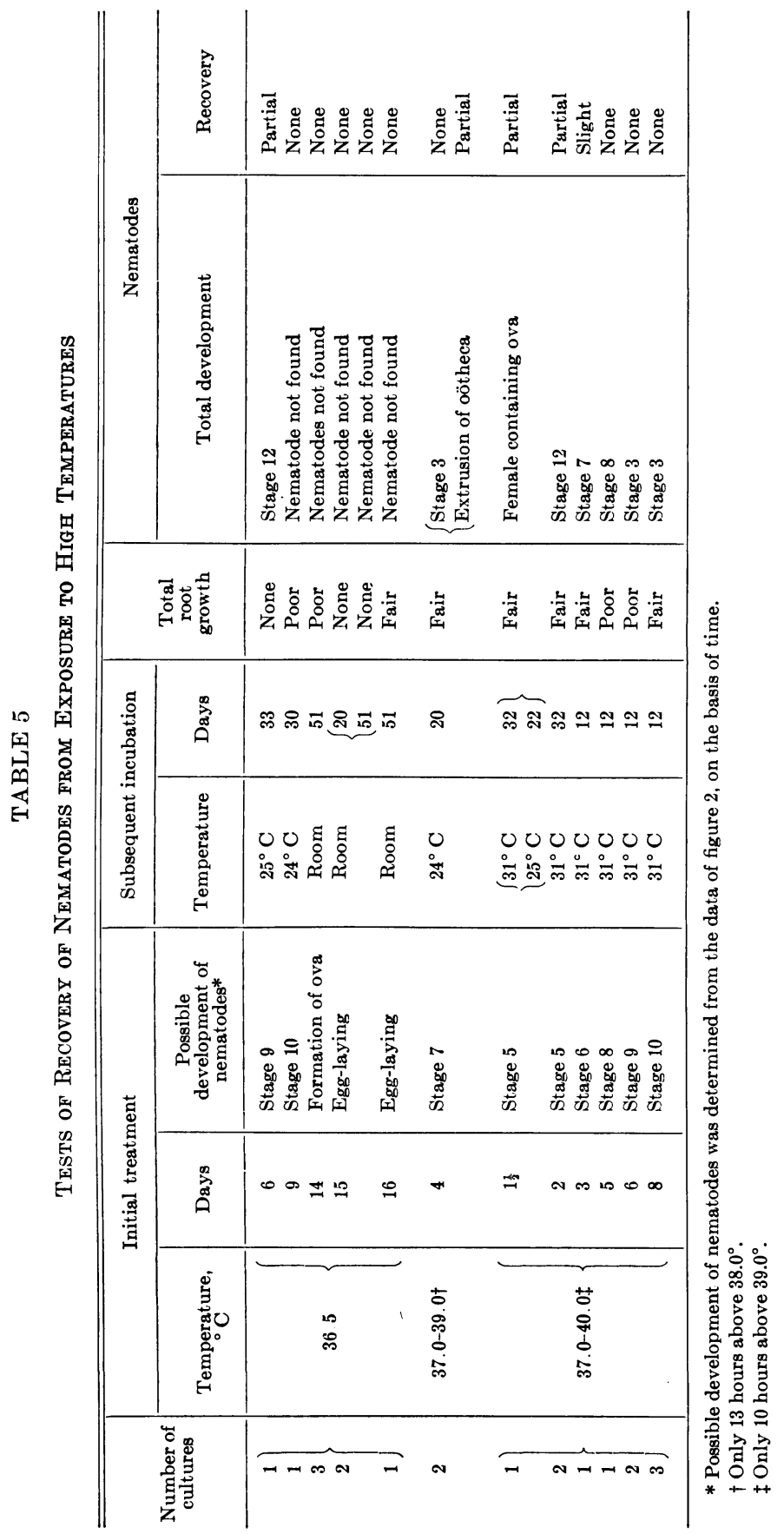


there was no development but probably death in the larval stage. The roots were stunted by the high temperature, and only 2 of them made new growth during the period allowed for recovery at room temperature. In 13 other cultures (table 5) exposed for shorter periods at $36.5^{\circ}$ to $39.0^{\circ}, 5$ nematodes made some recovery, but only 1 female formed ova and these were only partially developed.

The records are clear on the subject of recovery, although the nematodes were not examined until the end of the experiment. Their possible development during the time of the initial treatment was tabulated by analogy with the cultures (fig. 2) which showed the greatest development for the given number of days, although as a matter of fact, development is retarded at such a high temperature. If at the end of the experiment a nematode showed more development than was possible during the initial treatment, recovery was recorded. Three of the 5 nematodes showing recovery had suffered only the shortest exposures at the high temperature, and only 1 of the 5 had a theoretically possible development during that treatment beyond stage 8 , while the nematodes which made no development at all were those which had suffered the longest exposures to the high temperature.

The irregular results shown in table 5 are to be expected at such an extreme temperature. On the evidence of the 55 complete or partial failures in culture-solution experiments, it is concluded that the maximum temperature for the development of the root-knot nematode in such cultures is around $36.5^{\circ} \mathrm{C}$.

Another culture-solution experiment (table 6) showed that an exposure of 5 days at $36.5^{\circ} \mathrm{C}$ did not kill nematodes which were already in more or less advanced stages of development. Young females continued to form viable eggs when returned to a medial temperature after the exposure. There was some unhealthy development after a 7-days' exposure at $36.5^{\circ}$. Possible development during the initial incubation at $25.0^{\circ}$ was calculated by analogy with other cultures at medial temperatures on the basis of heat-unit counts.

It is barely possible that certain resistant individuals might develop at slightly higher temperatures in healthier roots. Indeed, in a preliminary experiment in 1925, 2 females reached stage 12 at temperatures around $40^{\circ} \mathrm{C}$. The host plants were growing in jars of infested soil, with their tops in the cooler air of the room. The thermostatic control was accurate, and the other data from this preliminary experiment were similar to those in the later experiments; but because there was no arrangement for circulation of the heated water around the jars, none of the records are tabulated here. 


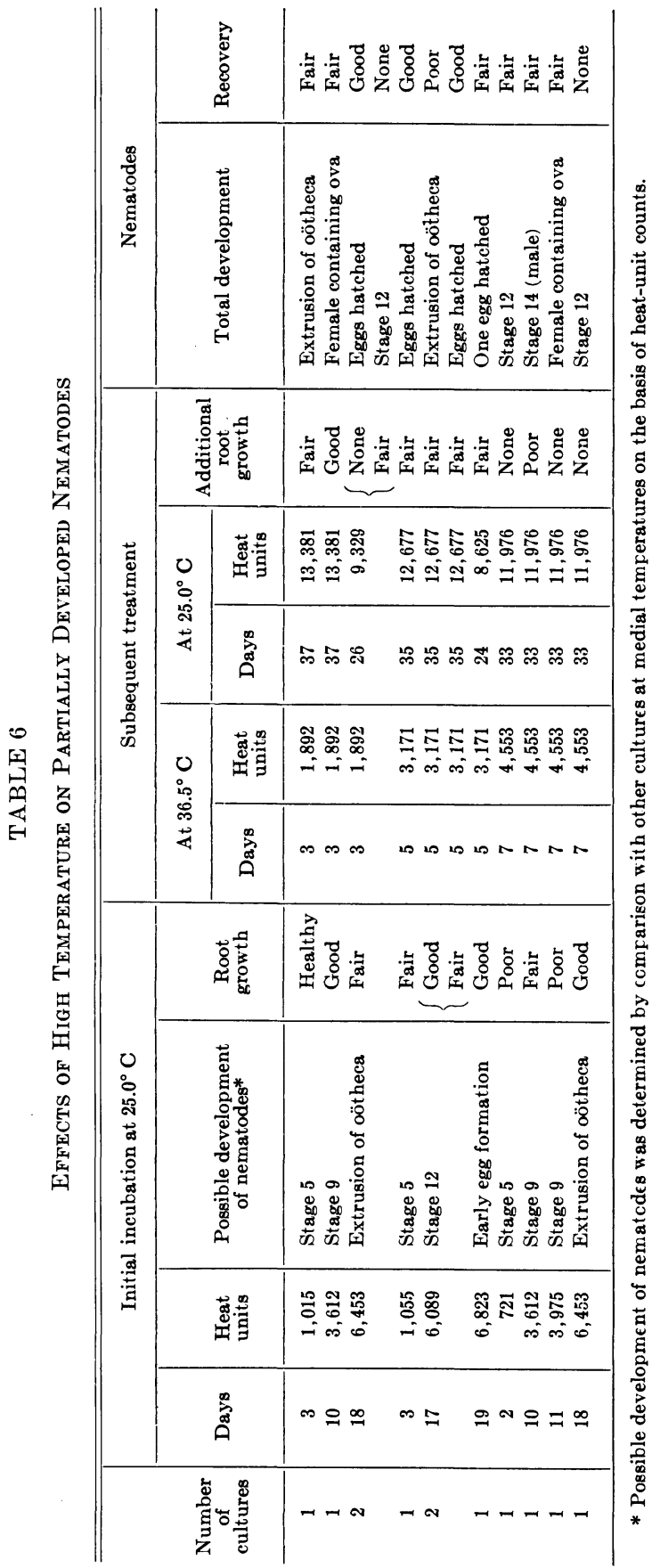


The limit of survival for many animals is around $40^{\circ} \mathrm{C}$. Other experiments with nematodes at high temperatures have used only the freeliving stages, so that it is not certain whether the high temperature was directly lethal, or whether death was caused by exhaustion of food reserves, as Baunacke (1922) suggested. Frandsen (1916) found that at $40^{\circ}$ development of eggs of the root-knot nematode was accelerated for a short time, and that some eggs hatched before the embryos were completely developed, but that after 18 hours at this temperature all eggs and larvae were dead. Hoshino and Godfrey (1933) report that larvae of this species were killed in water at $40^{\circ}$ in 2 hours and 15 minutes. Baunacke (1922) found that larvae of the sugar-beet nematode became rapidly exhausted at $29^{\circ}$ and above, but that motion continued feebly in some individuals up to $37.5^{\circ}$ and even to $39^{\circ}$ if heated very gradually. Although all larvae were quiescent at $40^{\circ}$, most of them were able to recover slowly from a short exposure at that temperature.

The fact that the optimum temperature is found so far below the maximum is probably related to the temperature conditions most often occurring in nematode-inhabited soils.

\section{ROOT PENETRATION AT HIGH TEMPERATURES}

Root-penetrating activity of larvae continued at high temperatures, though the results were somewhat irregular. In the 1927 experiments with plants growing in soil, there were 26 roots at $33.0^{\circ}$ to $35.0^{\circ} \mathrm{C}$ without galls, and only 6 roots attacked, in which 8 nematodes were found at stages 5,6 , and 7 , and 17 at stages 8,9 , and 10 , though they had all had time for further development. There was also a male at stage 14 . One gall was found on a root which had been 42 hours in infested soil above $40.5^{\circ}$. From the preliminary experiments of 1925 there are records of 4 galls formed at $40.0^{\circ}$, containing nematodes at stages 8 and 9 .

Most of the galls formed in petri-dish cultures at $35^{\circ} \mathrm{C}$ appeared after 1 or 2 days of incubation (table 10). After this galls were not formed at the high temperature, but some of the larvae survived a 5 days' exposure and were again capable of active root penetration when the plates were removed to a medial temperature. Later development of the nematodes was not affected by the conditions of this experiment.

\section{COMPUTATION OF RATE OF EGG-LAYING}

The rate of egg-laying was reported by Bessey (1911) as 10 to 15 or more eggs a day, without reference to the temperature, and by Byars (1914) as one egg an hour, or one in 50 minutes under the heat of a strong microscope light. 
In calculating the rate of egg-laying in my experiments, two methods were used. The first was a trial-and-error method. The number of heat units required for development to the beginning of egg-laying was calculated for 301 females (fig. 3), most of which had laid more than one egg. It was found that an allowance of 12 heat units per egg gave the most consistent results.

The second method, used to check the first, was based on a comparison of pairs of records. If two females cultivated at the same temperature developed at the same rate, they would reach the stage of egg-laying

\section{TABLE 7}

Variation in Time Required for Development of Nematodes from Gall Formation to EgG-Laying in Culture-Solution Experiments

\begin{tabular}{c|c|c|c|c}
\hline \hline $\begin{array}{c}\text { Temperature, } \\
{ }^{2}\end{array}$ & Days & $\begin{array}{c}\text { Heat } \\
\text { units }\end{array}$ & $\begin{array}{c}\text { Number of } \\
\text { cultures }\end{array}$ & $\begin{array}{c}\text { Eggs } \\
\text { laid }\end{array}$ \\
\cline { 1 - 2 } 25.0 & 20 & 7,017 & $1^{*}$ & 2 \\
24.5 & 19 & 6,562 & $1 \dagger$ & 5 \\
24.5 & 19 & 6,746 & 1 & 2 \\
24.0 & 24 & 8,018 & 2 & 7 \\
24.0 & 25 & 8,357 & 2 & $6 \ddagger$ \\
24.0 & 25 & 8,125 & 1 & 8 \\
23.5 & 21 & 6,698 & 2 & 8 \\
\hline
\end{tabular}

* Culture B of table 8. Culture A of table 8. (see table 3).

Under identical conditions, other nematodes laid from 34 to 121 eggs

with the same number of heat units. On this assumption, if one culture is examined at the beginning of egg-laying and the other is allowed a longer period of development, the difference in number of heat units between the two cultures would correspond to the difference between the two egg counts, and indicate the heat requirements for laying that number of eggs.

However, the rate of development is not the same for all females. Table 3 shows the wide variation in amount of development for the same time and temperature, and table 7 shows the range of time, measured in heat units, required by different nematodes at approximately the same temperature for the same amount of development. Table 3 includes some of the records of very slow development which were omitted from table 1.

Since it would obviously be inaccurate to compare two females for rate of egg-laying unless their rates of development were practically the same for the entire life history, it is necessary to interpret the differences. Simple inspection of the data in tables 1 and 2 shows which cul- 
tures made rapid and which slow development. Of the 10 records given in table 7, the culture showing the shortest time to egg-laying is called $\mathrm{A}$, and a somewhat slower culture, $\mathrm{B}$, was selected as having a rate more representative of the group. The 13 "longer-time" cultures at the same temperature, which had from 15 to 390 eggs apiece, were compared with $\mathrm{A}$ and with $\mathrm{B}$, as illustrated for 2 of them in table 8. The first of these, No. 4910, averaged 10.7 units per egg when compared with A, and 9.4

TABLE 8

Method of Calculating the Number of Heat Units for EgG-Laying

\begin{tabular}{|c|c|c|c|c|}
\hline & \multicolumn{2}{|c|}{$\begin{array}{l}\text { Comparison with short- } \\
\text { time culture A }\end{array}$} & \multicolumn{2}{|c|}{$\begin{array}{c}\text { Comparison with short- } \\
\text { time culture B }\end{array}$} \\
\hline & Eggs laid & Heat units & Eggs laid & Heat units \\
\hline Longer-time culture No. 4910 & 390 & 10,687 & 390 & 10,687 \\
\hline Short-time culture & 5 & 6,562 & 2 & 7,017 \\
\hline Difference & 385 & 4,125 & 388 & 3,670 \\
\hline Heat units per egg & $\ldots . .$. & 10.7 & $\ldots \ldots$ & 9.4 \\
\hline 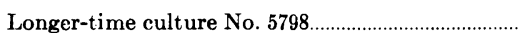 & 15 & 7,178 & 15 & 7,178 \\
\hline Short-time culture & 5 & 6,562 & 2 & 7.017 \\
\hline Difference & $\overline{10}$ & $\overline{616}$ & $\overline{13}$ & 161 \\
\hline Heat units per egg & $\ldots$. & 61.6 & $\ldots$. & 12.4 \\
\hline
\end{tabular}

when compared with $\mathrm{B}$, indicating that the entire rate of development of this culture was more rapid than that of $\mathrm{B}$, and even perhaps of $\mathrm{A}$. In the second comparison shown in table 8, culture No. 5798 approached the rate of $B$, as shown by the average of 12.4 heat units per egg, as against 61.6 units when compared with $\mathrm{A}$. The small number of eggs makes the difference in average number of units per egg more striking, but the retardation indicated by this high average probably occurred throughout development, and should not be referred entirely to the period of egg laying.

Similar comparisons were made with pairs of cultures at $29^{\circ} \mathrm{C}$. In most cases at both temperatures, one of the comparisons gave a result between 10 and 20 units per egg, though there were two instances of development so slow that both comparisons gave absurdly high results. It was concluded from this calculation also that 12 units per egg is a reasonable allowance. This would be 1 egg an hour at $22^{\circ}$, or 12 eggs a day at $16^{\circ}$. 


\section{RATE OF DEVELOPMENT OF EGGS}

To give information on the complete cycle, the rate of embryonic development was investigated. Recently deposited egg masses from culture-solution experiments were returned to the incubators and watched for larvae. Another and more exact method was to observe the development of individual eggs in distilled water or saline solutions, sealed in hanging-drop cultures. Table 9 reports both of these experiments. There is individual variation, as in all biological material, and the data are less

TABLE 9

Time Required for Development and Hatching OF EGGS IN Vitro

\begin{tabular}{c|c|c}
\hline Temperature, ${ }^{\circ} \mathrm{C}$ & Days & Eggs \\
\hline & $9-11$ & 16 \\
\hline 29.5 & $9^{*-11}$ & 22 \\
27.0 & $12-13$ & 21 \\
26.5 & $12-15$ & 14 \\
25.5 & $15-17$ & 10 \\
Rom & 26 & 9 \\
17.5 & $28-31$ & 17 \\
17.0 & $31^{*}$ & 7 \\
\hline
\end{tabular}

* Record of minimum time at this temperature plotted in figure 2 .

extensive than those on other stages of the life cycle, but they give a consistent curve (fig. 2). Eggs hatched after 9 days at $27.0 \mathrm{C}$ and after 31 days at $16.5^{\circ}$, counting from the 1 or 2-celled stage.

Godfrey and Oliveira (1932) report hatching of eggs in 5 days, at a temperature around the optimum, in galls on cowpea. This is a much shorter time than is found in any of my records, but since these authors allow 19 days before the discovery of the egg mass, the length of the entire cycle, 24 days in their experiment, is only one day less than my most rapid case.

\section{RATE OF ROOT PENETRATION}

The length of time required for gall formation at different temperatures is shown in table 10 and figure 2 . As soon as plate cultures were started with one active larva beside a seedling in a petri dish (for method see Tyler, 1933), the plates were placed in an incubator chamber and examined for galls at 12-hour intervals. Galls were formed in plates at 
$15^{\circ} \mathrm{C}$ in a minimum of 4 days. The rate increased at higher temperatures, and at $35^{\circ}$ macroscopic galls were found within 21 hours. That actual entrance into the root probably occurred sooner than this is indicated by the stained preparations of Godfrey and Oliveira (1932), which demonstrate larvae inside the root tips of cowpea and pineapple

TABLE 10

\begin{tabular}{|c|c|c|}
\hline Temperature, & Days & $\begin{array}{c}\text { Number of } \\
\text { larvae penetrating } \\
\text { roots }\end{array}$ \\
\hline 35.0 & $\begin{array}{c}0.8 \uparrow-1.0 \\
1.5-2.5 \\
3.5\end{array}$ & $\begin{array}{r}5 \\
22 \\
1\end{array}$ \\
\hline 23.8 & $2.0 \dagger-7.0$ & 8 \\
\hline 19.5 & $\left\{\begin{array}{c}2.0 \dagger \\
3.0-6.0\end{array}\right.$ & $\begin{array}{r}1 \\
12\end{array}$ \\
\hline 16.5 & $\begin{array}{l}3.0 \dagger-4.0 \\
5.0-11.0\end{array}$ & $\begin{array}{l}7 \\
9\end{array}$ \\
\hline 16.0 & $6.0-7.0$ & 2 \\
\hline 15.5 & $3.0 \dagger$ & 1 \\
\hline 15.0 & $\begin{array}{r}4.0 \dagger-6.0 \\
11.0-14.0\end{array}$ & $\begin{array}{l}6 \\
3\end{array}$ \\
\hline $\begin{array}{l}14.5 \\
14.0\end{array}$ & $6.0 \dagger$ & 1 \\
\hline & & \\
\hline
\end{tabular}

\footnotetext{
* There is also a record of gall formation in soil in 42 hours or less at $40.5^{\circ}$ to $44.0^{\circ} \mathrm{C}$, and another in 14 days at $9.0^{\circ}$ to $12.2^{\circ}$.

t Record of minimum time at this temperature plotted in figure 2 .
}

6 hours after inoculation, although galls did not appear until nearly 2 days had elapsed. The discrepancy between the time of root penetration and the appearance of the gall was not so great in my plate cultures. The root tip became opaque while the nematode was still only partly buried in its tissue, and a definite swelling appeared a few hours later.

\section{SUMMARY}

The minimum time required for the life cycle of the root-knot nematode from larva to larva in experiments in tomato roots was 25 days at $27.0^{\circ} \mathrm{C}$, increasing to 87 days at $16.5^{\circ}$. Development from gall formation to egg-laying required 15 days at $27.0^{\circ}$ and 79 days at $14.3^{\circ}$. 
The velocity curve shows acceleration of rate of development with rising temperatures through the medial range, and marked retardation of the average rate above $28.0^{\circ} \mathrm{C}$, although cases were found which showed practically the same rate at $31.5^{\circ}$ as at $27.0^{\circ}$. Below $16.5^{\circ}$ development was relatively more rapid than the average shown by the velocity curve. There are also considerable variations in rate of development for individual nematodes, possibly related to their nutrition.

As a working guide for all stages, heat units were computed as hourdegrees above $10^{\circ} \mathrm{C}$. Development to egg-laying required from 6,500 to 8,000 such units.

Root penetration by larvae in soil occurred at temperatures as low as $12.0^{\circ} \mathrm{C}$. Early development occurred as low as $9.5^{\circ}$ in cultures, indicating that the threshold of development is around $9^{\circ}$. After newly formed galls had been stored for 77 days at a temperature of $7.0^{\circ}$, a few of the nematodes were still able to develop normally at room temperature. No eggs were laid below $14.3^{\circ}$, but whether this limitation was related to temperature or to nutrition was not determined. The threshold temperature for maturity and egg-laying appears to be higher than for the early stages of the life cycle.

Serious injury to developing individuals in cultures was found at $36.5^{\circ} \mathrm{C}$, possibly correlated with the condition of the host plant. Free larvae, however, were still capable of root penetration after 5 days in plates at $35.0^{\circ}$, and one gall was found in soil above $40.5^{\circ}$. Eggs were not laid above $31.5^{\circ}$.

The rate of egg-laying was computed roughly as one egg per hour at $22.0^{\circ} \mathrm{C}$, or 12 units above $10.0^{\circ}$ for each egg laid.

Eggs developed from the 1 or 2-celled stage to hatching in 9 days at $27.0^{\circ} \mathrm{C}$ and in 31 days at $16.5^{\circ}$.

Root penetration and gall formation in petri-dish cultures required 4 days or more at $15.0^{\circ} \mathrm{C}$, decreasing to 21 hours at $35.0^{\circ}$.

\section{ACKNOWLEDGMENTS}

Grateful acknowledgment is made to Professor W. B. Herms for ecological interpretations as well as for counsel on the manuscript, and to Dr. W. M. Hoskins for assistance with apparatus and with analysis of data. 


\section{LITERATURE CITED}

\section{BAUNACKe, W.}

1922. Untersuchungen zur Biologie und Bekämpfung des Rübennematoden Heterodera schachtii Schmidt. Arb. Biol. Reichsanst. Land und Forstw. 11:185288.5 pls.

Bessey, E. A.

1911. Root-knot and its control. U. S. Dept. Agr. Bur. Pl. Ind. Bul. 217:1-89. 4 tables. 3 pls. 3 text figs.

Byars, L. P.

1914. Preliminary notes on the cultivation of the plant parasitic nematode, Heterodera radicicola. Phytopathology 4:323-326. 1 pl.

Cook, W. C.

1927. Some effects of alternating temperatures on the growth and metabolism of cutworm larvae. Jour. Econ. Ent. 20:769-782. 4 tables. 7 figs.

DeAN, A. L.

1929. Root-observation boxes. Phytopathology 19:407-412. 4 figs.

Frandsen, P.

1916. Eelworm parasites of plants. California State Comm. Hort. Mo. Bul. 5: 60-63. 1 fig.

GLenN, P. A.

1922. Relation of temperature to development of the codling-moth. Jour. Econ. Ent. 15:193-199. 6 tables.

GoDFrey, G. H.

1926. Effect of temperature and moisture on nematode root knot. Jour. Agr. Research 33:223-254. 8 tables. 17 figs.

Godfrey, G. H., and J. Oliveira.

1932. The development of the root-knot nematode in relation to root tissues of pineapple and cowpea. Phytopathology 22:325-348. 2 tables. 12 figs.

Hoshino, H. M., and G. H. Godfrey.

1933. Thermal death point of Heterodera radicicola in relation to time. Phytopathology (in press).

Jones, F. R., and W. B. Tisdale.

1921. Effect of soil temperature upon the development of nodules on the roots of certain legumes. Jour. Agr. Research 22:17-32. 4 tables. 3 pls. 4 text figs.

JoNes, L. H.

1932. The effect of environment on the nematode of the tomato gall. Jour. Agr. Research $44: 275-285.5$ tables. 1 fig.

KROGH, A.

1914. On the influence of the temperature on the rate of embryonic development. Ztschr. Allg. Physiol. 16:163-177. 6 tables. 8 figs.

Livingston, B. E., and H. S. FAwCETT.

1920. A battery of chambers with different automatically maintained temperatures. Phytopathology 10:336-340. 1 table. 
Ludwig, D.

1928. The effects of temperature on the development of an insect (Popillia japonica Newman). Physiol. Zool. 1:358-389. 6 tables. 9 figs.

PARKER, J. R.

1930. Some effects of temperature and moisture upon Melanoplus mexicanus mexicanus Saussure and Camnula pellucida Scudder (Orthoptera). Montana Agr. Exp. Sta. Bul. 223:1-132. 42 tables. 25 figs.

Peairs, L. M.

1927. Some phases of the relation of temperature to the development of insects. West Virginia Agr. Exp. Sta. Tech. Bul. 208:1-62. 31 tables. 19 figs.

SHELFORD, V. E.

1927. An experimental investigation of the relations of the codling moth to weather and climate. Illinois Nat. Hist. Survey Bul. 16:311-440. 28 tables. 34 figs.

TYLER, J.

1933. Reproduction without males in aseptic root cultures of the root-knot nematode Hilgardia $7: 373-388.6$ tables. 